\title{
Emergence of Water Urbanism for Water Born “Can Tho"
}

\author{
Ayasha Siddiqua \\ Department of Architecture, Ahsanullah University of Science and Technology, Dhaka, Bangladesh \\ Email: ayasha9735@gmail.com
}

How to cite this paper: Siddiqua, A. (2019) Emergence of Water Urbanism for Water Born "Can Tho". Journal of Water Resource and Protection, 11, 166-180. https://doi.org/10.4236/jwarp.2019.112010

Received: November 26, 2018

Accepted: February 10, 2019

Published: February 13, 2019

Copyright $\odot 2019$ by author(s) and Scientific Research Publishing Inc. This work is licensed under the Creative Commons Attribution International License (CC BY 4.0).

http://creativecommons.org/licenses/by/4.0/

\begin{abstract}
Growing from water, Can Tho is a region on delta area of Southern Vietnam carved up by the currents of Mekong's tributary, where settlements and water are closely interact. Being an important city, Can Tho puts in high expectations for investment calls that activate the growth of the city towards a new direction of urbanism. This trend seems to neglect its nature way of coping with water. In this connection, the intention of the research is to understand the urbanism in delta area of Can Tho, its confidences and fears the region has to experience and deal with. The intensive field work reveals an evaluation towards Can Tho's spatial quality and major water problems. As a closing, the last section has share thoughts that different strategies of urban design to retrieve back the wisdom of living with water which are required for future urbanity of Can Tho region.
\end{abstract}

\section{Keywords}

Urbanism, Settlement Pattern, Infrastructure, Water Problems, Water Urbanism

\section{Introduction: Involving Water in Urbanism}

Water is indispensable "stuff" for maintaining the metabolism, not only of our human bodies, but also of the wider social fabric [1]. A society established devoid of water is almost impossible. Without water there is no humankind, without humankind there is no evolving civilization [2]. From the plan of Dinocrates for Alexandria (331 B.C.) to the plan of L'Enfant for Washington, the plan for St. Petersburg, the definition of the city was unconceivable without water [3]. For this reason, water has become one of the focal points for new attempts to conceptualize the materiality of urban space [4]. As the environmental crises are rising in the changing world in the last two decades, peoples are also more concern on the impact of urban areas in the environment. In this continuation of 
environment sensitive approaches, the urban designers also started to investigate the traditional communities to find their water resource management. It is the deviation that water bodies induce in the regular ordinariness of the built fabric that generates the most striking spatial quality of many water based cities.

Growing from water, Can Tho, a region on delta area of southern Vietnam carved up by the currents of Mekong's tributary, is one example of embryonic urban practices where settlements and water closely interact. The region develops in rapid on a land of productive landscape. However, as the heart of Mekong delta, Can Tho is put in high expectations for investment calls that activate the growth of the city towards a new direction of urbanism, which tendency seems to neglect its nature tendency in coping with water. In addition, external pressure from the climate change has put Can Tho region to encounter its crisis of being exist on its vulnerable land. This publication is intended to understand the water urbanism in delta area of Can Tho, its confidences and fears the region has to experience and deal with. Inventories of maps field works reveal intriguing findings which reveals an evaluation towards Can Tho's spatial quality and major water problems. As a closing, the last section will share thoughts that different strategies of urban design, which incorporate the wisdom of living with water, are required for future urbanity in Can Tho region.

\section{Water and Bountiful Land of Mekong Delta}

The Mekong delta is located in the region of southwest part of Vietnam where world's one of the longest rivers Mekong approaches and makes this delta resourceful with its distributed networks (Figure 1). Being gifted by natural water and land resources Mekong delta is one of the most important agricultural and aquaculture production region of Vietnam which produces half of the total rice grows in this country, known as "rice basket" and 60 percent of fish production for all of Vietnam and accounts for 27 percent of Vietnam's total GDP. The mighty Mekong River in its last segment in Mekong delta with its enormous branches nested this extremely flat delta region (with elevation rising on average only about one meter $(1 \mathrm{~m})$ from the South China Sea to the international border at Châu Đoc) and the only source of fresh water with special ecological and hydrological characteristics. Water flow of Mekong River, heavy monsoon, tidal up and down of nested rivers by Gulf of Thailand in the west and the South China Sea intimately tied their life with water. All of these water forces shape this delta by sedimentation and tidal forces. Recognized by themselves as "river-water civilization" or "canal-creek civilization", Mekong delta clearly demonstrates the rich water landscape in this tropical wetland. Mekong Delta is the most downstream area of Mekong basin and it covers the nearly $5 \%$ of the basin.

The largest river in south-east Asia-Mekong River originated from Tibet Mountains about 2800 miles away and after passing through 6 countries it reaches to the South China Sea through Mekong Delta in Vietnam territory. Mekong River distributes great influences to agriculture, especially paddy fields 

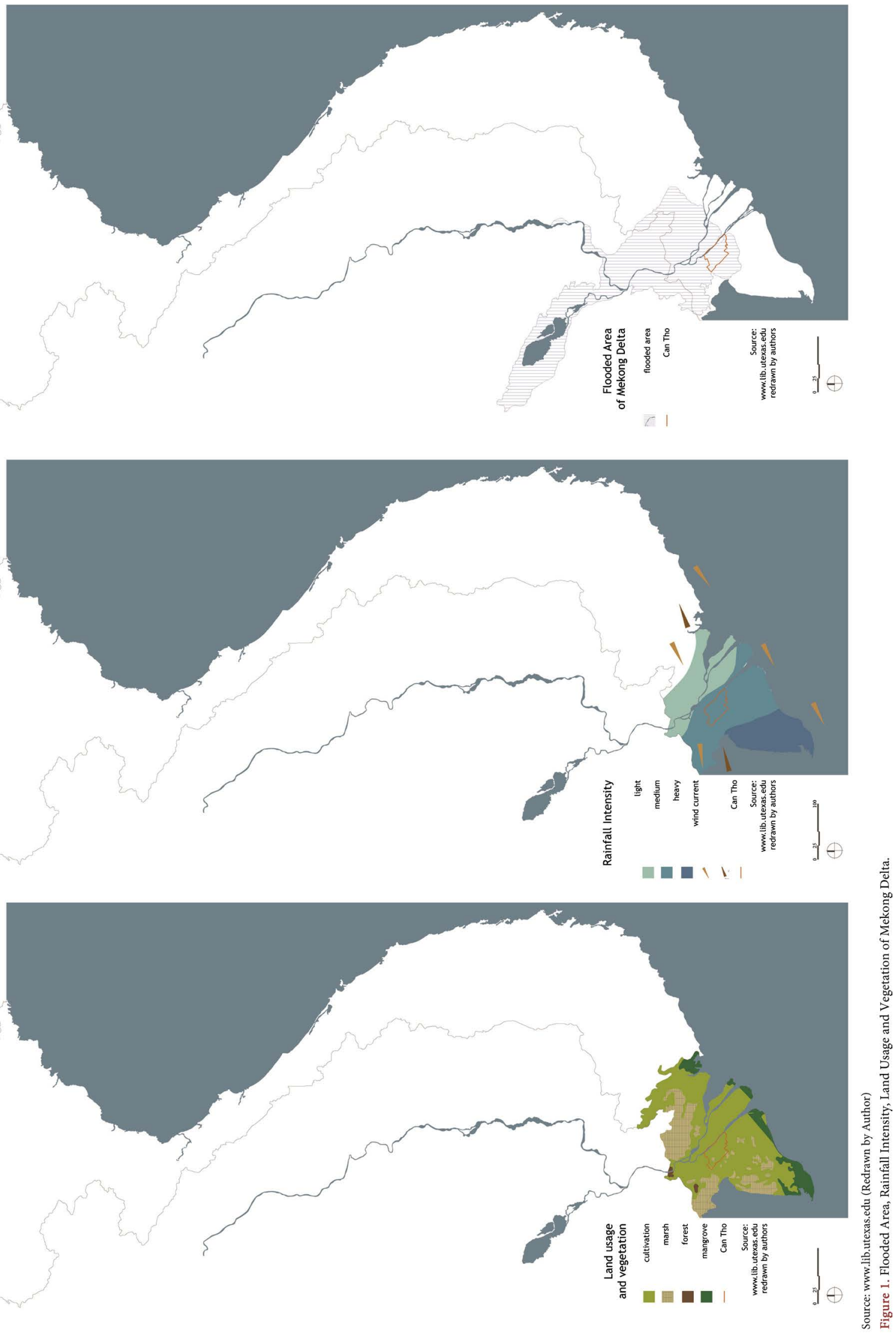
there. With two seasonal variations in high season and low season where water volume differs up to $70 \%$ - $75 \%$, this river generated its stream mainly from intraregional rainfall and riverhead ice melting. As the delta is bordered the Gulf of Thailand in the west and the South China Sea in the east also has great influence of the hydrological character in this region and affect the water flow over 100 kilometers in inland. The Great Lake (Tonle Sap) in Cambodia also plays a very important role for regulating water flow to the downstream which takes the inflow water from Mekong River during high season and influence the water flow in downstream in dry season. This also affects the flood in Mekong delta and lengthens the flood period. Being low in elevation this delta periodically flooded by rising Mekong River and water inflow due to tidal force of surrounded seas that make the land fertile by sedimentation. So, their unique water features crisscross this land by waterways for many miles making the delta extremely fertile, productive and sustainable for both in agriculture and aquaculture [5].

The unique landscape setting of this region also helps to make it more productive. There are huge back swamp areas in lower Mekong basin which greatly varies in size and influence the water features also. Connected with the main rivers through canals and distributors, these swampy areas take the water from rising rivers which act as natural flood regulator. Silt deposition makes the land fertile and productive. The landscape here also altered in many ways from its start over two million years ago in the late tertiary period. Through settlements, public work and warfare, human have changed almost every aspect of this fluid landscape.

New technology and ideas transferred the water environment into a hybrid, human-natural environment through mechanization, irrigation and new species of crops, wild plants and animals. Now the interior landscape are subdivided into many cells of manmade and natural canals, which though increase the flood penetration into inside areas but at the same time, make the land alluvial with sedimentation. People adjusted themselves with changed environment condition by changing paddy typology from short-term rice to floating rice and practicing fish firming. Richest natural agricultural land along the freshwater alluvial land flash by main rivers and creeks, orchards in the narrow long bank depicted lusciously green and beautiful landscape with seasonal variation.

\section{Can Tho-Regional Urbanism of Delta Area}

\subsection{Brief History: Indigenous Water Village, Power Regimes and the Shifting Boundaries}

Named as Tran Giang firstly, Can Tho was situated on map of Vietnam in 1739, when the China imperialism under Qing Dynasty was still dominating the country until the late $18^{\text {th }} \mathrm{C}$. Its strategic position on the bank of Hue river, lower tributary of Mekong River flowing from China, had constructed the city as both the center of economic and military defense activities from its hostile competitors, 
Siem and Chan Lao. In the late of $18^{\text {th }} \mathrm{C}$, when Tran Giang was extensively heard for its vigor wealth and armed forces, chaotic changes of leadership occurred to occupy the flourishing city.

In a while before French crossed the threshold, Binh Thuy area became Tran Giang indigenous, where the natural landscape inspired the civilization. Rivers denoted significantly as transportation medium, at the same time as they became an orientation or point of reference of the settlement patterns. The waters were distributed for irrigation usage for the cultivation areas through smaller ditches. Trading centers were built and on the waterways nodes, supporting temporary activities of floating markets. It was the era when water civilization was truly prominent. In late $15^{\text {th }} \mathrm{C}$, Can Tho expanded toward the mid and lower land of Hau River. Trading centers flourished in the early of $19^{\text {th }} \mathrm{C}$ causing the most prominent feature of waterway civilization. Floating market took place in waterway junctions in Tra On, Phong Dien, and Cai Rang.

The thriving small realm attracted the French to try residing in the late of $19^{\text {th }}$ C. Colonial city typology was located in Ninh Kieu area, which now is the center of Can Tho, close to the mouth of Can Tho and Hau River, and Binh Thuy. Centrality of European old cities configuration was implemented in a formal, hierarchical, and grid pattern. Administrative buildings were accompanied by the other public buildings and open space facilities. Improvement of infrastructure, such as water channels development and electricity power supplies, and managing tropical storms were developed by French. During French colonialism in later of $19^{\text {th }} \mathrm{C}$ and early $20^{\text {th }} \mathrm{C}$, with interventions from Saigon, major change caused administrative boundary shifting until the war against them. After Geneva agreement in 1954, US entered Vietnam. Independence search during US governance after French occupation did not stimulus the city that much, except the strengthening of military base and improvements and construction of land and air connections. In 1991, democratic republic of Vietnam national assembly released a decree on parting Hau Giang into two provinces: Hau Giang and Can Tho. At last, since 2004, Can Tho's region as remains until present is run under central governance.

\subsection{Contemporary Can Tho}

- Terrain: Can Tho is created by alluvial soil sedimentation of Hau River, with even and flat terrain which is gradually low towards northwest-southeast direction (towards the sea of Hau River) and northeast-southwest direction (from Hau River to inland). At present, the city terrain is hollow at some places. On the edge of Hau River, the area is $1.0-1.5 \mathrm{~m}$ higher. Along the national road $\mathrm{N} 80$, the topography has $0.8 \mathrm{~m}$ more height, and $0.5 \mathrm{~m}$ higher only in O Mon in the river farm area. Areas near river banks are always high and get gradually low towards far distance.

- Soil condition: Fertile soil with mineral content and neutral $\mathrm{pH}$ is disposed in the most area of Can Tho. Therefore, the usage is suitable predominantly 
for agriculture, which total cultivated land is 116,867 ha [6]. Soil types are classified into two major types, alluvial and non-alluvial soil. Four soil types are found: clay, plastic clay, peat, and river sand. Brick and building material industries exploit clay and sand soil type.

- Agriculture and aquaculture: Extensive area of agriculture dominates the land usage in Can Tho. Rice fields consumes almost the north and west area, while orchards and annual crops are cultivated in the south of Can Tho. Fish farms are found following the strand of Hau River from middle to north Can Tho. Seasonal inland fish farms are located close to the main irrigation cannels using small front part of the rice fields.

- Hydrology: Watercourses are streaming all over the region in Can Tho with total length of $650 \mathrm{~km}$. Hau river passes $75 \mathrm{~km}$ long through Can Tho, which is $41 \%$ output of Mekong River [6]. Neighboring and cultural ambience, sometimes functions as drainage system is the task for smaller rivers. The rest of the waterways in the agricultural areas supply the water for irrigation and can also useful for boat passage (Figure 2).

- Inundated areas: Water level in Can Tho waterways is influenced by the hydrology of Hau River, rainy season, and tide and weather from the South China Sea although the region is located $80 \mathrm{~km}$ from the sea. The difference of highest and lowest tidal reaches the number $1.70 \mathrm{~m}$ during the ebbing tide. The rising level of the water has also caused flooding in the city as the city does not have sufficient quality of dike/protection and improper drainage systems.

- The water hierarchy: There are several classifications of the watercourses to explain the roles. Large scale watercourses, carrying heavy duty industrial purposes and transport medium for large water vehicles. Medium scale watercourses, serving more local mobility and cultural happenings, as the most important rivers for each district. Small to medium size industries are as well found along these rivers. Small scale watercourses and canals, including here is the navigable irrigation channels, where the people in the neighborhood and village transfer their agricultural goods. Watercourses in Can Tho have

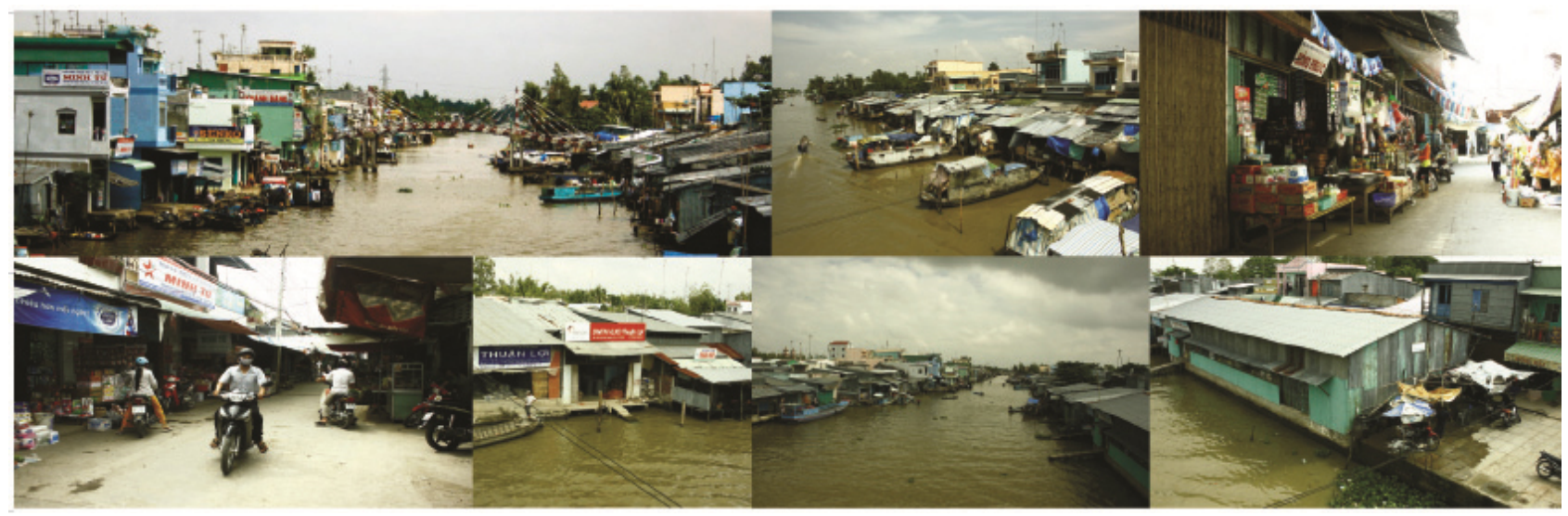

Figure 2. Settlements closely related with water. 
been a benchmark to set up every typology of the settlements (Figure 3). The first layer, the indigenous settlements, was discovered along the waters. When the infrastructures were more improved, the layer settlements altered to follow the infrastructures lines. Present development and urbanization are more based on the infrastructure, less concern about water. The informal settlements are mushrooming towards the water, directly facing the roads. The spaces for the waters have reduced gradually, replaced by permanent constructions. For many years, Can Tho has always faced the flooding problems during the high tide and rainy season. For that reason, recent developments tend to have higher platform or filled area to prevent the water disturbance. The former settlements and development are usually lower than the new constructions, which are very weak to be potentially flooded. Water problems have the tendency to be solved individually rather than planning an integrated and efficient solution. River banks of the rivers vary from soft to hard edge. Some of the banks are protected with walls to prevent the river erosion, while most of the banks are allowed to alter smoothly with soft edge of vegetation. The soft edge river banks are defenseless and inviting informal settlements to occupy.

- Land infrastructure hierarchy: Several types of land based infrastructure according to users, road width, connections, and locations (Figure 4).

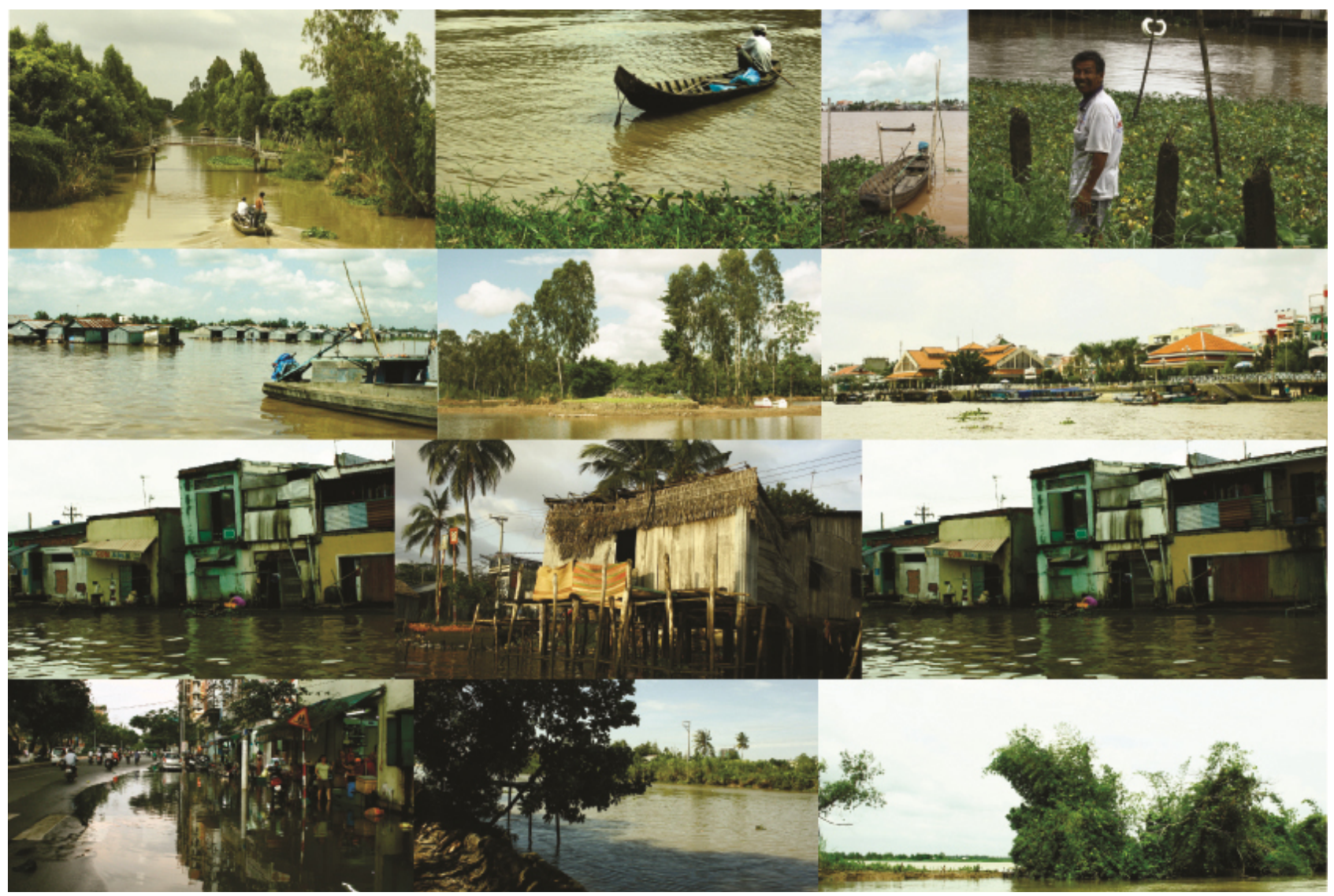

Figure 3. Water hierarchy of Can Tho City. 


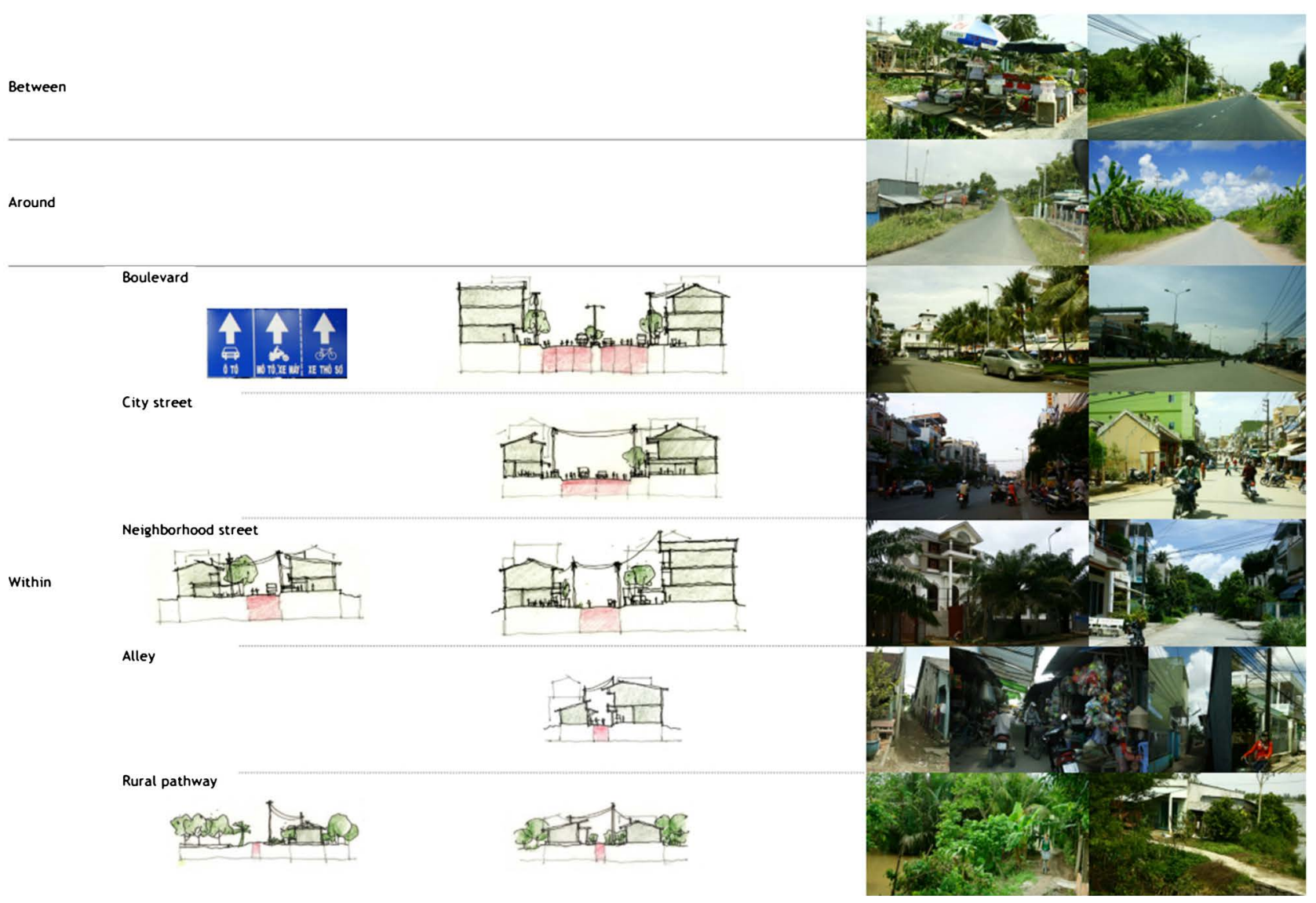

Figure 4. Land infrastructure hierarchy of Can Tho City.

Between: international and interregional access. International route is used by heavy vehicles. Buildings are set few meters away back from the road with less concentrated. Resting places, fish farms, and seasonal agriculture are found on both sides of the road. The road offset area is often used for temporary agriculture.

Around: inter district connection: Each district is linked with a single primary road. Following the intensity between high to low urbanization, the roads vary for their width, quality, presence of pedestrian access, and the (badan jalan).

Within: internal connection: Main boulevard 10 - 15 meter width main boulevard is divided into three lanes for each direction: four-wheel vehicles, motorcycles, and bicycles. Spacious pedestrian path is found along the road with lines of trees. This pedestrian path was mostly constructed recently, and mostly higher than the buildings. Main boulevard is expected to distinct the visual quality, as main public and government buildings, cultural places, commerce, and private residences are set along the roads. Informal activities of temporary kiosks as well complement the liveliness of the streets. City street as secondary link, with less intensity, city street has the nature to rather replicate main boulevard's road experience, with smaller walkway and trees. Ground floor area of each building generally opens straight to the street to welcome the profit possibilities. Some buildings will expand their properties temporarily following the timing of the 
busy markets. Neighborhood street entering the neighborhood, the road becomes less frantic and extensive. Building typology from the city street is repeatedly brought to the neighborhood with less commerce at ground floor are. Privacy and security needs are materialized with gates and fences, clearly separating the street, giving the houses another level of seclusion.

Alley: Narrow alley branches from the busy streets. Fronting on lean street corridor, this small access is sometimes constructed with gravels and stones, accessible only for pedestrians and two wheel vehicles. Proximity between the houses differs from 3 - 5 meter. Space at ground floor or front part of the house is usually given for small selling function.

Rural pathway: In the rural area, thin pathway appears as gravel or dirt road, enabling the houses and farmlands to access the higher roads. Plots of building are smaller but less dense, with vegetation barrier for each compound's privacy. Drainage system very seldom comes with the roads.

\subsection{Concluding the Observation}

Water is the identity of Can Tho. Through years the dwelling process has been always recruiting water as the main concern: water as the source of living, culture, emotions, place making, and nature. Can Tho is destined to be living with water. However, the role of water is decreasing. Infrastructure improvements bring another reference for new development. Rapid urbanization without any limits has created the type of a spontaneity, fragile, and uncertain urbanity. Another additional factor is the external pressure from the environment. The rise of the sea level pushes Can Tho to receive flooding, extreme weather, erosion, and salinity intrusion within and into the region.

\section{Way to Sinking}

\subsection{Mekong Delta}

The Mekong delta, one of the most productive agricultural areas in the world, within the very complex hydrological system, is facing extreme changes and environmental disordered day by day. Due to great stream coming from Mekong River, close vicinity to sea, low land elevation, and dense distributions of water courses make it more common for flooding and other water related disasters. Now a day, this delta faces extreme flood events which are more frequent during wet months; draught, salinity (sea water) and acid intrusion into soil in dry season; drinking water shortage; frequent storms; river erosion, destruction of natural wetland and loosing biodiversity. Water controlling dams in the upper stream, ice melting in mountain peak due to earth temperature rise, changing climatic condition, sea level rise, extreme population changes and migration, occupying the natural wetland and forest for agriculture and construction are assuming the major reasons for these water related disasters. By 2050, more than 1 million people will be directly affected in the Mekong Delta from risk through coastal erosion and land loss, primarily as a result of the decreased sediment 
delivery by the rivers, but also through the accentuated rates of sea-level rise [7]. And with the sea level rise about $1.0 \mathrm{~m}, 31 \%$ area (12,376, 7 sq.m) and $26.7 \%$ population (4,786,600 no) of Mekong River Delta will be affected (Figure 5) [8].

The Climate Change Research Institute, at Can Tho University, has introduced a script of climate in the Mekong Delta in the next 20 years. There they mentioned that due to more reduction of rainfall in dry season and late coming rainy season will make the draught of Mekong Delta severe by 2030. In some coastal provinces rainfall will reduce by more than $25 \%$. Due to draught sea water is penetrating into mainland including arable land which will be severe with the coming fiercer draught. Due to insufficient fresh water flow in the Mekong River cannot displace saline intrusion from soil. For some provinces, near to sea remain extensively salinized for 4 - 6 months a year. ICEM estimated that with sea level increase by $100 \mathrm{~cm}$, the salt concentration will increase $10.3 \mathrm{~g} / \mathrm{l}$. In the wet months, almost $50 \%$ of the delta is flooded. Flood will be very vibrant and unimaginable in coming future both the degree of severity and the frequency. Heavy rainfall in rainy season along with sea level rise, flood will be more serious. During rainy season 2/3 areas of Mekong Delta will be submerged with $1.00 \mathrm{~m}$ sea water level raise. Ben Tre province will be mostly affected with $51 \%$ inundation whereas Can Tho will be submerged by $24.7 \%$ by 2030 among the most affected province in Mekong Delta [8].

Moreover, construction of water structure like dike, hydropower dams in the uppers stream increasing the velocity of rivers which causing river bank erosion, increase flooding in the unprotected areas and also causing failure of river edge protection engineering in the protected areas. Construction of dams and natural
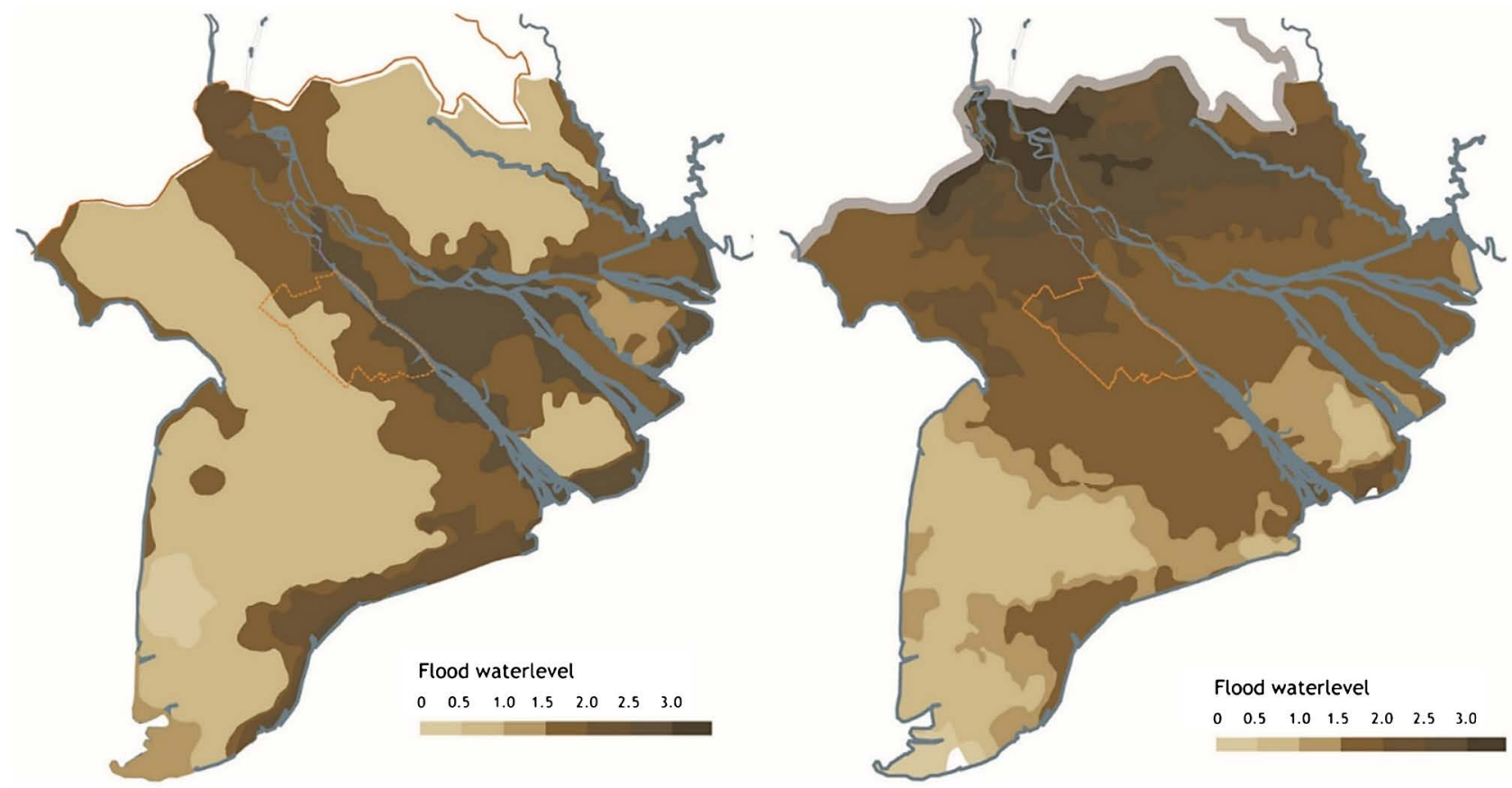

Source: IMEC, 2008 (Redrawn by Author).

Figure 5. Flood map in Mekong delta in wet season and $1 \mathrm{~m}$ Sea Level Rise Scenario. 
distortion also lengthen the flooding period in downstream.

\subsection{Can Tho}

Located on the hub of Mekong delta Can Tho, the biggest and one of the major city of the region also suffers from flood, draught, salt intuition, ecological destruction which are further worsening by sea level rise and global climate change. Sited on the west bank river Hau-one of the bigger branches of Mekong River, the city also has a dense system of rivers and canals serving for agriculture, aquaculture, navigation and water supply and others for the region. Increasing urbanization, industrialization, pressure on agriculture land, huge migration pressure, alteration of natural land and water courses for more profitable production purpose also considering manmade reasons these natural disasters and make this city one of the most vulnerable localities in the Mekong region. Sea level rise is accelerating all of these environmental problems. It has been estimated by International Center of Environmental Management that with the 1 $\mathrm{m}$ sea level rise $758 \mathrm{~km}^{2}$ area will be flooded which is $24.7 \%$ of total area of Can Tho city and population affected by 426,511 no, about $20.80 \%$ of total pop of the province (Figure 6) [8]. Huge population need to be displaced from the affected area and will create unimaginable pressure on the remaining land.

Can Tho's $65 \%$ living in rural and sub-urban areas. The water and land structure is totally different in urban rural area. In rural area most of the natural water courses have been altered with dense network of canals to drain off the floodwater from arable land as quickly as possible province (Figure 7). Though this is advantageous for agricultural production, it also increases the flood vulnerability in the low elevated rural, sub-urban region at the same time increase saline intrusion into arable soil. As mentioned earlier, the landscape here are arrange with huge back swamp areas which are connected with large rivers by branches allow to enter flood water inside but the large incoming upstream

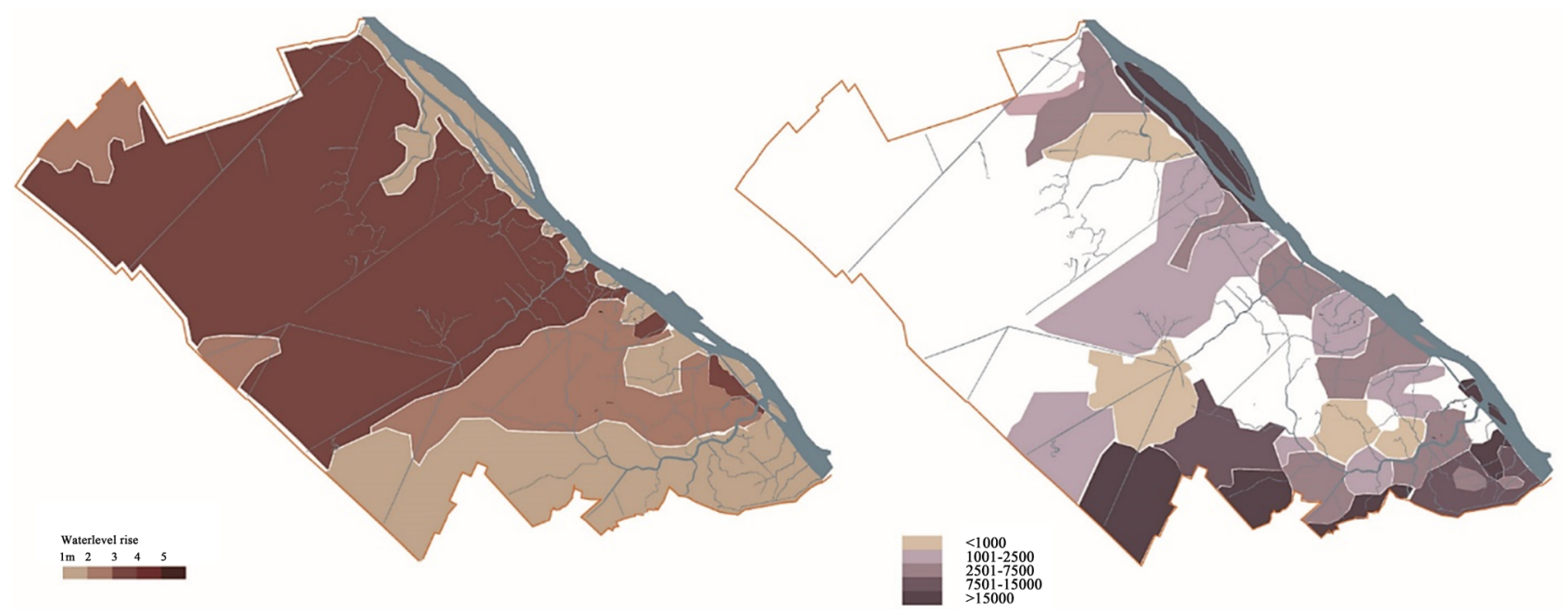

Source: IMEC, 2008 (Redrawn by Author).

Figure 6. Inundation zones with $1 \mathrm{~m}$ SLR scenario and population displaced by $1 \mathrm{~m}$ SLR 


\section{Poor drainage system by improper urbanization causing urban flooding \& water logging by heavy monsoon, tidal rise and sea water level increase:}

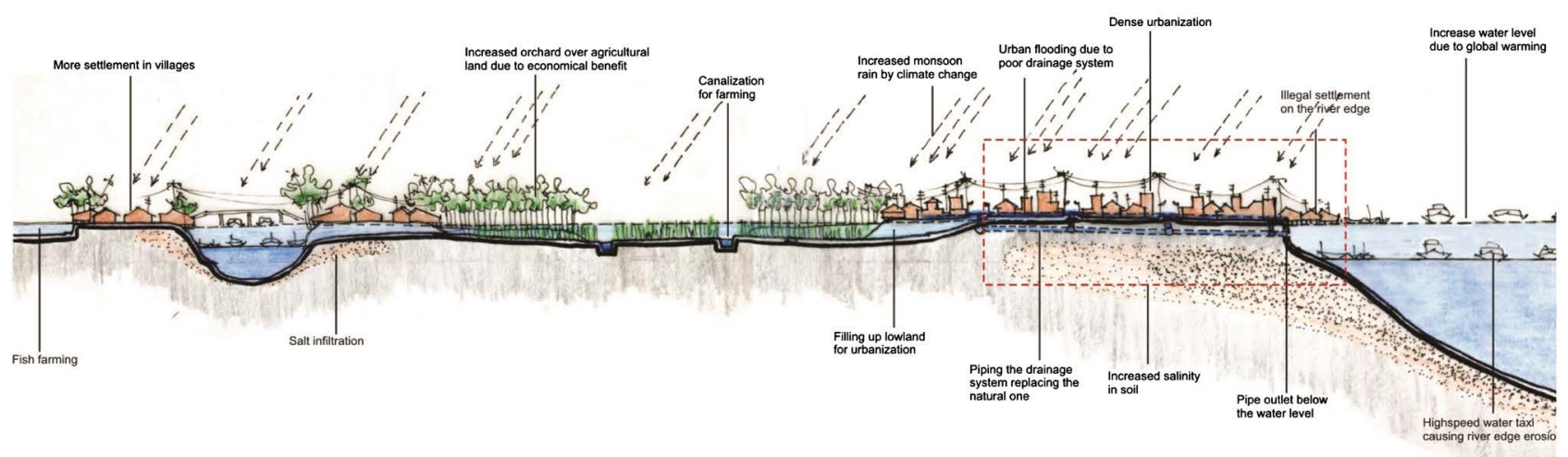

Smooth network between big rivers and inside lowland with natural drainage system helped to tackle the flooding by water rise:

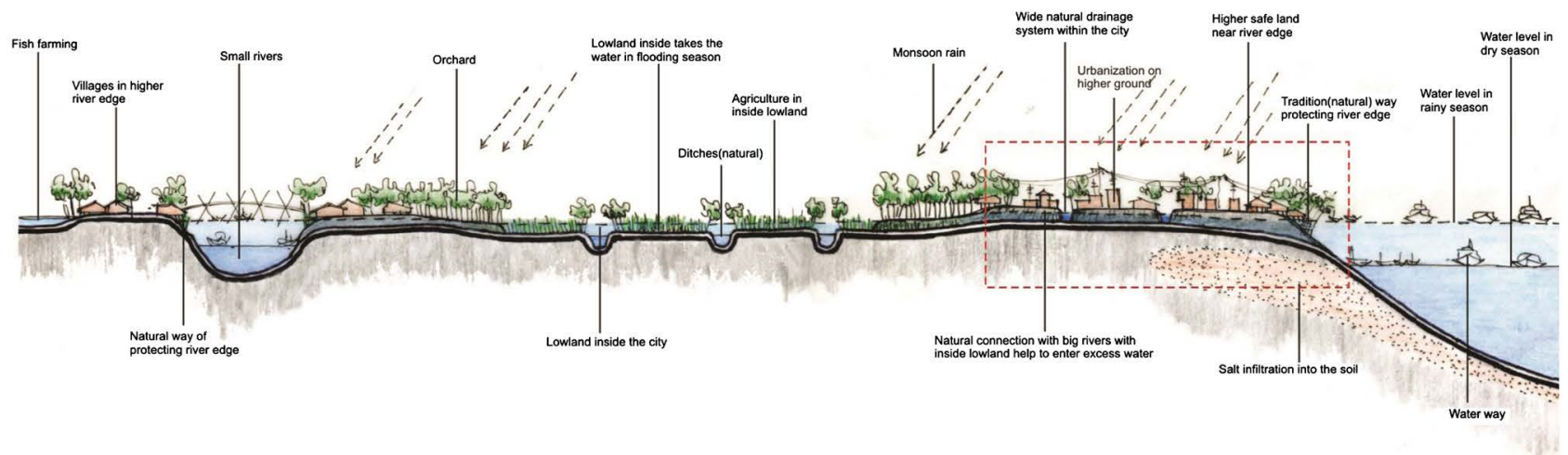

Figure 7. Landscape alteration from past to present make the land scope for flooding.

water from Mekong River, intense rainy season and sea water level rise make flooding scenario more dangerous during wet season. The poor rural people living in the edge of river and river branches that are relatively higher than the inside swamp area. But with the increasing flooding level rise they are not safe in the relatively $0.8 \mathrm{~m}$ to $1.5 \mathrm{~m}$ higher ground and this is also beyond their affordability to make the base higher and consequently inundation is very common for several weeks to months every year. But in the dry season, there are shortages of fresh water from the only source of Mekong River become severe problem for rice cultivation. Reduction of discharge from river lower the ground water table which eventually increase the acidity into soil water causing great damage for agriculture and aquaculture. People living there also suffer from severe shortage of drinking water. Moreover, due to lack of fresh water, saline water of sea travel through the drainage canals by the tidal movement and salinity intrusion is very common in dry season hampering the rice cultivation. Local people trying to prevent flood water penetration, quick drainage of excess water, flash out the acid soil and saline water intrusion by increasing drainage network and introducing dam on their way. But these have further threat to the soil fertility, speed of soli degradation, changing of ecological feature of these wetlands.

The flooding scenario in concreted urban area is different than the rural country side. Being located in most important site for air-water-road traffic, Can 
Tho's economic structure is now reforming towards industrialization and urbanization. In 2007, Can Tho's economic structure included $41.23 \%$ of industry and construction and $43.62 \%$ of commerce and the rest for agriculture, forestry and fishery [5]. City's modern center Ninh Kieu district is the highest densely populated area which is crowded with many administrative buildings, domestic houses, commercial institutions and others organizations. The nearby districts like Binh Thuy, Cai Rang, Omon and Tra Noc are also gradually occupied by housing developments, industrial zones, and commercial developments. It is rear to find open water-green spaces with public facilities within these busy districts. The quantity of salt water from South China Sea entering Mekong delta has increased over the past years as the change of global climate. With $1 \mathrm{~m}$ SLR scenario or even higher, salinity disputes will force farming activities to either stop or change to an adaptive brackish vegetation or farms.

Huge road infrastructures are introducing in this fastest growing city which is the only open space in urban area. In urban area, city already loses its natural drainage structure and has converted to underground piping system. Wide natural branches connected to the bigger water channels replaced by narrow pipes are totally insufficient to drain out huge, increased rain water in wet months. Moreover, the asphalt carpet in urban area has disconnected the inside swamp areas with large rivers which interrupt to take the excess water of river in high level season and during high tidal moment. So, water takes place in the urban street-the only open space in urban area and low elevated built areas through the drainage pipes. Eventually, water logging is very common in the heavy rainy season and every evening during high tidal months. The least water channels are also occupied by illegal settlements and converted to open waste disposal creating big obstruction for water drainage. Moreover, present huge urbanization and industrial development are taking place on the natural lowland just filling up those randomly. Due to this practice, Can Tho is gradually destroying its wetland that acted as natural flood regulator and also losing the absorptive capacity (Figure 7).

\section{Closing: Emergence of Urban Design}

As the population is increasing, land sinking due to sea level rise, people displaces from the more affected area to comparatively higher land in the upstream, huge environmental change by the global climate change creating large pressure on land. Being one of the major cities in Mekong Delta, Can Tho is experiencing these extreme changes those are accelerating very rapidly. The city is now going forward to accommodate growing people by rapid urbanization, huge investment in the industrial sector to bust-up war-affected economy, uncounted land infrastructure to prepare the land for development. These urbanization and industrialization are growing without following any planned and organized way and creating huge urban problems. The deterioration of city environments has been devastating, in particular with regards to the use of water-different water 
related environmental disasters like flooding, draught, pollution; lack of open spaces for city relief (Figure 8). The random half-hazard urban practices are destroying the rich water tresses of this land.

To restore the environmental quality for people and nature, tackle water related disasters, improve flooding condition, and survive from sinking; new attitude and approach is imperative towards land structuring for future urbanization. As water logging and flooding within the city is the reason of improper water network and destroyed drainage system, reading the unique water-landscape and restore them is vital now. Nature sensitive urban design is essential where land-water consider in a sustainable way; urban design, engineering and management need to form a team in a new and integral way. Landscape and waterscape of the city and their heritage strongly required restore by reading previous condition. How to deal with water in a more logical and sustainable way-that could be the key issue of this conscious urbanism. By providing solution for existing water problems the nature and water-based urbanism might help to reinvent water based traditions to integrate present and future requirements of water management, ecology and open space development. New urbanism needs to be structured by the logic of landscape and waterscape, integrating
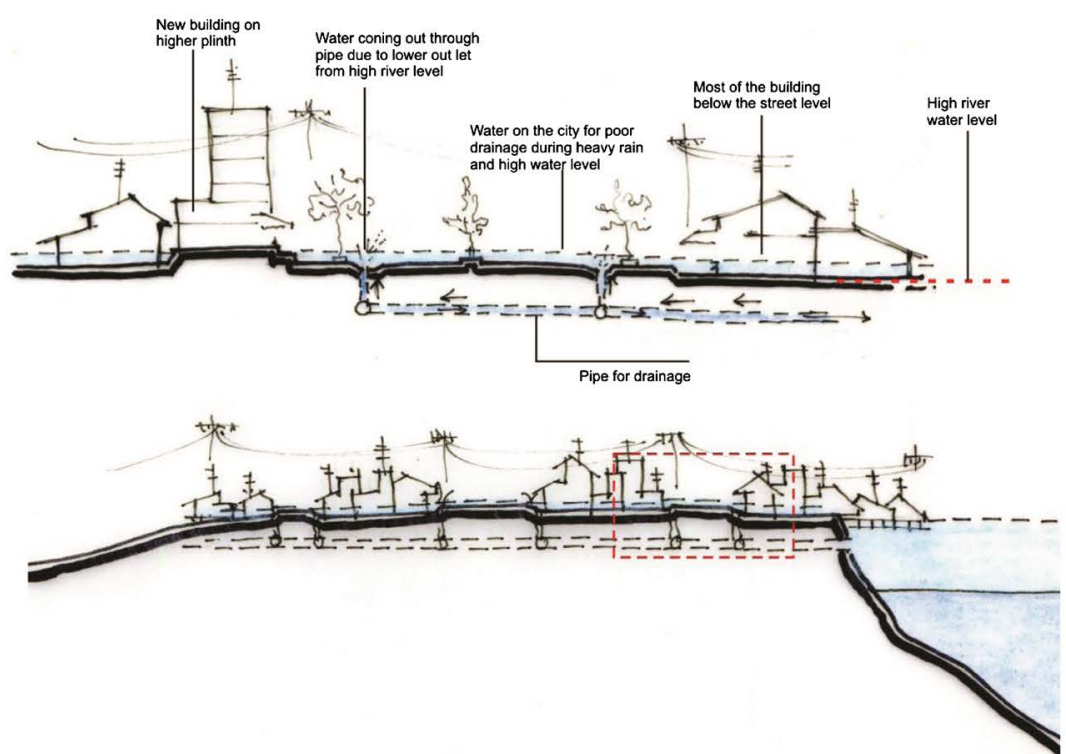

In previous natural drainage within city and with the big rivers to inside lowland helped to tackle flooding

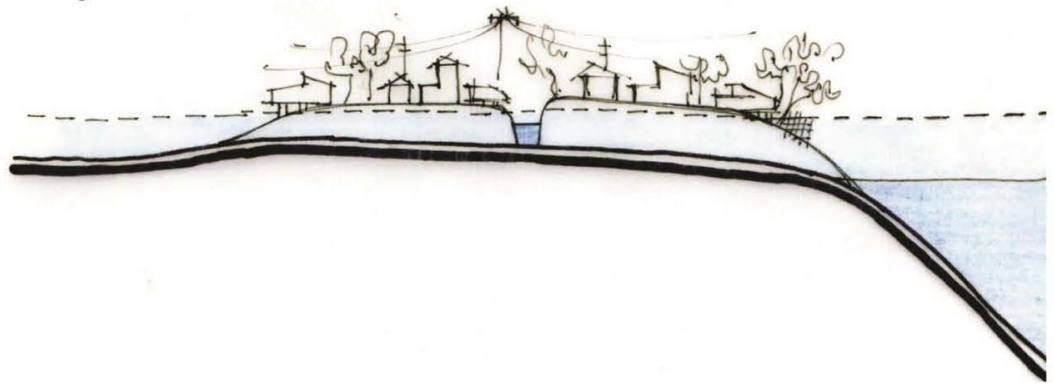

Figure 8. Water taking the built area as urbanization occupying its place.

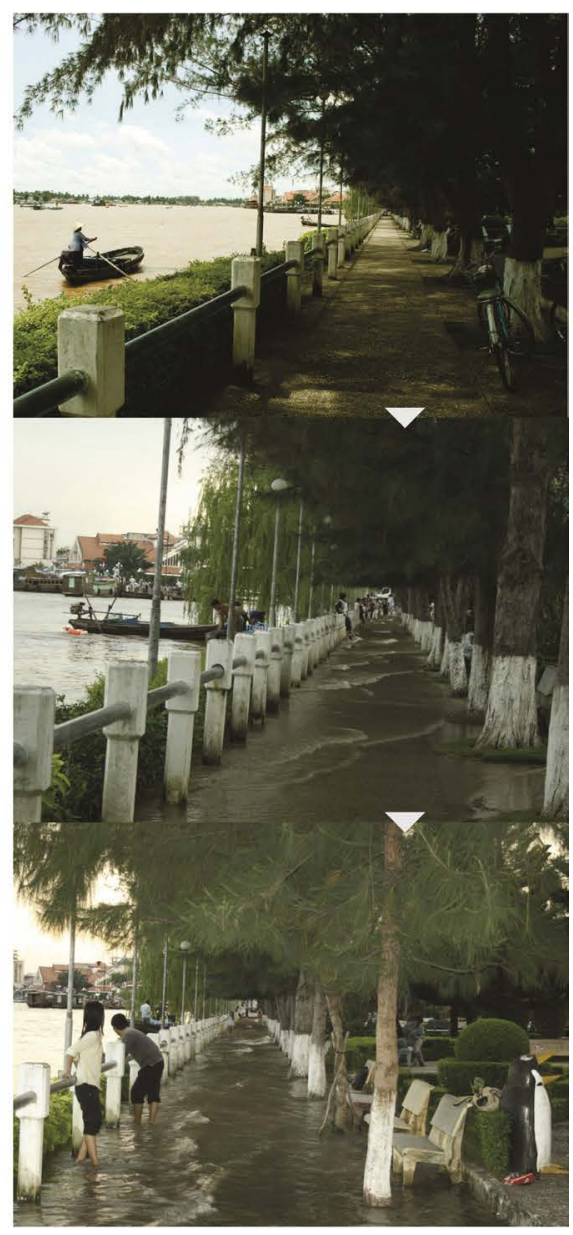


environmental consideration into urban planning.

"Landscape urbanism-understood as structuring landscape to guide their occupation, use and urbanization ... landscape urbanism whereby an integral system of urbanization is tied to the logics of landscape" [9].

\section{Acknowledgements}

This paper is the edited version of a small research conducted by author in Can Tho, Vietnam for three months. The research was funded by Flemish Inter-University Council (VLIR) under South-South Mobility Allowance. The promoter from Belgium Prof. Dr. Kelly Shannon and Arch. Ngo Quang Hung and Dr. Nguyen Ho Bac. Hung from SIUP (Southern Sub-Institute for Urban Rural Planning, HCMC, Vietnam) from Vietnam were always with their valuable guidance for this research.

\section{Conflicts of Interest}

The authors declare no conflicts of interest regarding the publication of this paper.

\section{References}

[1] Swyngedouw, E. (2004) Social Power and the Urbanization of Water-Flows of Power. Oxford University Press, Oxford, UK.

[2] Wybe, K. (2008) Transforming with Water. In: Proceedings of the 45 th World Congress of the International Federation of Landscape Architects, Blauwdruk, Wageningen/Techne Press, Amsterdam.

[3] Shannon, K. and Moulder, B.D. (2008) Water Urbanisms. In: Shannon, K. and Moulder, B.D., Eds., Martien De Vletter, Sun, Gent, Belgium, 6.

[4] Gandy, M. (2004) Rethinking Urban Metabolism: Water, Space and the Modern City. City, 8, 371-387. https://doi.org/10.1080/1360481042000313509

[5] Biigs, D.A. (2004) Between the Rivers and Tides: A Hydraulic History of the Mekong Delta, 1820-1975. Doctoral Thesis, University of Washington, Seattle.

[6] World Bank (2008) The World Bank in Vietnam, Safeguard Report, Project: Urban Upgrading, Document: Environmental Impact Asessement, Can Tho, December.

[7] Summary Report (2007) Climate Change Impacts and Vulnerabilities Assessment for Can Tho City. Prepared by Research Institute for Climate Change-Can Tho University and People's Committee of Can Tho City.

[8] ICEM (2008) International Center of Environmental Management (ICEM), Rapid Assessment of the Extent and Impact of SLR in Vietnam.

[9] Shannon, K. and Manawadu, S. (2007) Indigenous Landscape Urbanism: Sri Lanka's Reservoir \& Tank System. JoLA (Journal for Landscape Architecture), 2, 6-17. https://doi.org/10.1080/18626033.2007.9723384 